\title{
Effects of Supplementary Cementitious Materials on Properties of Cementitious Grouts: A Review ${ }^{\dagger}$
}

\author{
Nazmus Sakib ${ }^{1 *}$, Sudharshan N. Raman ${ }^{2}$, Azrul A. Mutalib ${ }^{3}$, M. Jamil ${ }^{4}$ and Daniel T. W. Looi ${ }^{5}$ \\ 1 Department of Civil Engineering, Universiti Kebangsaan Malaysia, 43600 UKM Bangi, Selangor, Malaysia; \\ sakib.khs@gmail.com \\ 2 Civil Engineering Discipline, School of Engineering Monash University Malaysia, Jalan Lagoon Selatan, \\ 47500 Bandar Sunway, Selangor, Malaysia; sudharshan.raman@monash.edu \\ 3 Department of Civil Engineering, Universiti Kebangsaan Malaysia, 43600 UKM Bangi, Selangor, Malaysia; \\ azrulaam@ukm.edu.my \\ 4 Department of Architecture and Built Environment, Universiti Kebangsaan Malaysia, 43600 UKM Bangi, \\ Selangor, Malaysia; pghinovasi@ukm.edu.my \\ 5 Faculty of Engineering, Computing and Science, Swinburne University of Technology (Sarawak Campus), \\ Jalan Simpang Tiga, 93350 Kuching, Sarawak; DLooi@swinburne.edu.my \\ * Correspondence: sakib.khs@gmail.com; Tel.: (+60189193915) \\ + Presented at the 1st International Electronic Conference on Applied sciences, \\ 10-30 November 2020; Available online: https://ecsa-6.sciforum.net/
}

Published: 10 November 2020

\begin{abstract}
Generally, grout is a combination of cement, sand, and water (with or without admixtures), which poses low viscosity and high penetrability. Grout is very suitable for anchoring application, jacking of concrete elements, grouting of ducts in prestressing application, application in narrow joints and many more. Nowadays it is used to provide additional strength to load-bearing structures. The grout characteristics includes the flow capacity in narrow space and physicalchemical compatibility with the substrate materials. However, shrinkage, stability, leaching of the grouts, etc. are the main problems of cement grouting. Supplementary cementitious materials (SCMs) such as fly ash, ground granulated blast furnace slag (GGBS), silica fume (SF) etc. can be used as admixtures in cement grout to reduce the problems associated with grout. This paper provides a review on the assessment of the flowability, strength, shrinkage and chemical resistance of the cementitious grouts containing SCMs, and its feasibility in grouting applications. This paper reveals that combination with SCMs in the production of cement-based grouts provides advantages in specific uses in concrete industry.
\end{abstract}

Keywords: Cement; Concrete; Grout; Flowability; Strength; Supplementary cementitious materials

\section{Introduction}

Nowadays cement-based grouts are used in many construction domains [1]. Grout is a construction material with filling ability in narrow spaces, and mostly used in repair and rehabilitation of concrete structures. Considering the wide-ranging applications of grouts, studies have recently been given attention to investigate the effects of various factors on quality and cost of grout [2]. Currently grouts are using in different construction applications, such as to reduce the flow of seepage, fixing reinforcing elements in pre-stressed concrete structures, to fill voids where concrete cannot reach, to fill cracks in massive concrete structures, to strengthen a foundation, rehabilitating defective masonries in historical buildings and so on [3].

Cement production requires a significant amount of materials from limited natural resources and generates a lot of greenhouse gas emission to the atmosphere, which leads to a severe 
environmental problem. On the other hand, industries produce tons of by-products and wastes $[4,5]$. Most of these by-products possess pozzolanic characteristics. By-products from several industrial processes can be used as supplementary cementitious materials (SCM) as a partial substitution of ordinary Portland cement (OPC) in concrete to reduce cement content and achieve durable and sustainable concrete [4]. SCMs are the materials that possess binding ability at room temperature, and which are used as partial replacement of OPC to have desirable performance. Most of the SCMs are by products of industrial or agricultural processes. Some natural minerals can also be used as SCM [6]. Use of SCMs in concrete offers a series of vital properties such as denser microstructure, better mechanical properties, lower heat of hydration, and lower shrinkage and cracking $[2,6]$.

SCMs have been utilized to produce cementitious grout in several studies. An effective use of SCMs in the production of cementitious grout requires optimization of different properties. The influences of different SCMs on the behavior of grout are summarized in this article to provide an overview about the trends of research in this field.

\section{Commonly used SCMs for grout}

Maximum of the SCMs are high in Silica $\left(\mathrm{SiO}_{2}\right)$, Alumina $\left(\mathrm{Al}_{2} \mathrm{O}_{3}\right)$ or Calcium oxide $(\mathrm{CaO})$ content. Natural Pozzolans also can be used as SCMs. Table 1 shows the commonly used SCMs by different authors in their experiments.

Table 1. Different type of SCMs used by the researchers.

\section{Different type of SCMs}

\section{Authors}

Fly ash (FA) 2002 [8]; F.S. Fonseca et al. 2015 [9]; T. Bilir et al. 2015 [14]; R. Saleh Ahari et al.

\section{Ground} 2015 [18]

Granulated A. Joshaghani et al. 2017 [2]; T.S. Krishnamoorthy et al 2002 [8]; R. Saleh Ahari et al. Blast furnace 2015 [18]

slag (GGBS)

A. Joshaghani et al. 2017 [2]; L.G. Baltazar et al. 2014 [3]; S. Erdog du et al. 2011 [7]; Silica fume (SF) T.S. Krishnamoorthy et al 2002 [8]; M.J. Shannag 2002 [10]; A. Hasan et al. 2012 [11] R. Bani Ardalan et al. 2017 [12]; R. Saleh Ahari et al. 2015 [18]

Pumice Glass powder A. Joshaghani et al. 2017 [2]; R. Bani Ardalan et al. 2017 [12]

Metakaolin

(MK)

Natural

Pozzolan (NP)
H. Güllü et al. 2017 [4]

A. Hasan et al. 2012 [11]; R. Saleh Ahari et al. 2015 [18]

M.J. Shannag 2002 [10]; Y. Senhadji et al. 2014 [15]

\section{Effects of SCMs in cementitious grout}

Fresh and mechanical properties of grout are significantly influenced by the physical and chemical characteristics of SCMs. Fresh properties indicate the flowability and consolidation nature, whereas hardened properties indicate mechanical strength and durability. Property like acid resistance provide a good indication about durability. This section discusses the effect of SCMs on properties of cementitious grout. General chemical properties of SCMs are provided in Table 2.

Table 2. Chemical properties of SCMs.

\begin{tabular}{|c|c|c|c|c|c|c|c|}
\hline $\begin{array}{c}\text { Chemical } \\
\text { Propertie } \\
\mathrm{S} \\
\text { (\% mass) }\end{array}$ & FA & GGBS & SF & MK & Pumice & $\begin{array}{l}\text { Glass } \\
\text { powder }\end{array}$ & $\begin{array}{l}\text { Natural } \\
\text { Pozzolan } \\
\text { (NP) }\end{array}$ \\
\hline
\end{tabular}




\begin{tabular}{|c|c|c|c|c|c|c|c|}
\hline - & $\begin{array}{c}\text { R. Saleh } \\
\text { Ahari et } \\
\text { al. 2015; } \\
\text { A. } \\
\text { Joshaghan } \\
\text { i et al. } \\
2017\end{array}$ & $\begin{array}{l}\text { R. Saleh } \\
\text { Ahari et al. } \\
\text { 2015; A. } \\
\text { Joshaghani } \\
\text { et al. } 2017\end{array}$ & $\begin{array}{l}\text { R. Bani } \\
\text { Ardalan } \\
\text { et al. } \\
\text { 2017; A. } \\
\text { Joshagha } \\
\text { ni et al. } \\
2017\end{array}$ & $\begin{array}{l}\text { A. Hasan et } \\
\text { al. 2012; } \\
\text { R. Saleh } \\
\text { Ahari et al. } \\
\quad 2015 ;\end{array}$ & $\begin{array}{c}\text { A. } \\
\text { Joshagh } \\
\text { ani et al. } \\
\text { 2017; R. } \\
\text { Bani } \\
\text { Ardalan } \\
\text { et al. } \\
2017\end{array}$ & $\begin{array}{l}\text { H. } \\
\text { Güllü et } \\
\text { al. } 2017\end{array}$ & $\begin{array}{c}\text { Y. } \\
\text { Senhadji } \\
\text { et al. } 2014\end{array}$ \\
\hline $\mathrm{SiO}_{2}$ & $59.5-61.3$ & $35.9-40.3$ & 86.2 & $51.1-63.53$ & $\begin{array}{c}51.2- \\
53.1\end{array}$ & 74 & 47.21 \\
\hline $\mathrm{Al}_{2} \mathrm{O}_{3}$ & $18.5-28.8$ & $10.2-12.1$ & 1.44 & $32.36-39.1$ & $\begin{array}{c}20.7- \\
21.2\end{array}$ & 1.30 & 18.85 \\
\hline $\mathrm{FE}_{2} \mathrm{O}_{3}$ & $4.98-6.96$ & $0.58-0.67$ & 0.2 & $0.54-2.15$ & 1.24 & - & 9.99 \\
\hline $\mathrm{CaO}$ & $1.05-3.24$ & $35.3-36.7$ & 3.06 & $0.29-0.30$ & $6-6.80$ & 10.50 & 10.84 \\
\hline $\mathrm{MgO}$ & $0.63-2.03$ & $6.9-10.2$ & 1.32 & $0.18-0.70$ & 1.6 & - & 4.38 \\
\hline $\mathrm{SO}_{3}$ & $0.13-0.47$ & $0.62-1.40$ & 0.34 & $0.01-0.08$ & 0.44 & - & 0.50 \\
\hline $\mathrm{Na}_{2} \mathrm{O}$ & $0.24-1.27$ & 1.12 & - & 0.11 & - & 13 & 0.81 \\
\hline $\mathrm{K}_{2} \mathrm{O}$ & $1.40-1.93$ & 0.97 & - & 1.78 & - & - & 0.20 \\
\hline L.O. I & 4.32 & 1.9 & - & $1.0-3.80$ & - & - & 3.91 \\
\hline $\begin{array}{l}\text { Specific } \\
\text { gravity } \\
\left(\mathrm{kg} / \mathrm{m}^{3}\right)\end{array}$ & 2200 & 2850 & 2350 & & $\begin{array}{c}2700- \\
2950\end{array}$ & - & 2.62 \\
\hline
\end{tabular}

${ }^{*} \mathrm{FA}=$ Fly ash, $\mathrm{SF}=$ Silica Fume, GGBS= Ground granulated blast furnace slag, MK= Metakaolin, NP=Natural Pozzolan

\subsection{Flowability}

The slump flow test is an important parameter to assess the flowability of cementitious mixtures. A mix with sufficient flowability reduces the cost and time for the construction process. The properties of SCMs on the flowability of mixtures are related with the replacement level. The viscosity and consistency of the cementitious mixtures improve due to the incorporation of SCMs. The cementitious mixtures containing SCMs also exhibited less bleeding and segregation [2]. The pore particles of pumice reduce the flowability slightly as it absorbs water and keep the rate of slump flow steady [2]. The flowability of the grouts containing a combination of natural pozzolan and silica fume enhanced significantly compared to the grouts containing silica fume or natural pozzolan alone [10]. Combining silica fume and natural pozzolan in cement-based grout reduces porosity and bleeding and improves the packing density [10]. It is reported that addition of MK increases the flowability of the cementitious mixture [11]. The particles of fly ash (FA) have relatively smoother surface and spherical shape compared to cement. Therefore, replacement of cement with FA reduces internal friction and thus increases the flowability of cementitious mix. The mixture containing $30 \% \mathrm{FA}$ showed higher flow with $42 \%$ less superplasticizer than the mix without FA [16]. It is also reported that silica fume (SF) shows a consistent reduction in flowability of mix up to $25 \%$ replacement [17].

\subsection{Strengths}

The strength of the grout is a property that provides a good indicator of its quality. Study showed that the strength of grout reduced slightly with increasing replacement level from 10 to $30 \%$ for pumice and fly ash incorporated specimens [2]. Some studies reported that fly ash and pumice mixed specimens experience lower strength at higher replacement ratios compared to other pozzolans [2, 7]. The slag mixtures exhibited higher strength than those of control mix due to high pozzolanic reactivity the slag [2]. In general, the strength of cementitious grouts containing SCMs is higher when compared with the grout containing normal Portland cement. Grouts replaced with SCMs, showed an increase in their compressive strength up to nearly $15 \%$ over the control mix [8]. 
SCMs exhibits both filler and pozzolanic effect. By providing a dense microstructure, reducing porosity the filler effect promotes to increases the strength of the grout. The pozzolanic effect helps in the formation of bonds between the densely packed particles in the transition zone through the pozzolanic reaction with the calcium hydroxide. Grouts with FA gains sufficient strength at lower replacement level [9]. Combination of filler and pozzolanic effect helped to increase in strength of the grouts [10]. However, with the increasing slag content, the compressive strength of the mix enhanced better than that of fly ash and pumice, which is owing to the higher pozzolanic reactivity of slag. The compressive strength of the concrete having $50 \%$ OPC, $40 \%$ pumice and $10 \%$ silica fume had $16 \%$ and $21 \%$ higher than the control mixture at the ages of 28 and 90, respectively [12]. However, the strength of the grout containing fly ash and pumice was reported lower compared to control mix $[12,13]$. This tendency was also stated previously by another researcher [2]. On the other hand, at $30 \%$ and $40 \%$ replacement ratios, mortar exabits higher compressive strength when FA used as fine aggregate [14].

\subsection{Shrinkage}

Cement is highly shrinkable, therefore high volume of cement affects the long-term performance of grout. Pozzolans are used as cement replacement materials to reduce the shrinkage. Due to high surface tension in SCMs an inward pulling force is generated in the internal wall of the capillary pores that reduces the volume of capillary voids $[4,5,11,18]$. When the capillary pores are high, concrete has much potential to shrink [5]. That is why fly ash and pumice shows higher tendency to shrink compared to SF and slag [2]. In shrinkage controlling performance, SF was proved to be more effective than slag $[2,8,11]$. SF and MK reduces the drying shrinkage of the SCMs mix with the increased percentage of MK or SF [11]. The use of FA delays the occurrence of shrinkage crack in mortars. FA as fine aggregate up to $70 \%$ reduce the crack widths significantly with the increase FA ratio in mixture [14]. All the previous researchers reported that the mixtures with SCMs are less potential to shrink compared to control mix due to less capillary void content.

\subsection{Chemical Resistance}

The durability of grout is as significant as the strength, the resistance capacity of SCMs grouts in acidic medium should be studied. The higher resistance of the mixtures containing SCMs against chemical attack is attributed to the pore refinement process occurring due to the conversion of lime through lime-pozzolan reaction. In addition to the pozzolanic reaction, the filler action of SCMs further densifies the pore structure to enhance the resistance. The cubes of pozzolanic grouts showed good resistance in sodium and magnesium sulphate $\left(\mathrm{Na}_{2} \mathrm{SO}_{4}, \mathrm{MgSO}_{4}\right)$ solutions without significant spalling even at the corners [10]. Mortars containing SF suffers up to $30 \%$ less weight loss than OPC mortar while exposed to $5 \% \mathrm{HNO}_{3}$ [15]. NP also provides resistance by about $17 \%$ in the same acidic medium. SF containing specimens also suffered less weight loss than OPC in $\mathrm{H}_{2} \mathrm{SO}_{4}$ medium. Whereas $15 \%$ NP offers $33 \%$ more resistance of cementitious grout against $\mathrm{H}_{2} \mathrm{SO}_{4}$ [15].

MK effectively reduced chloride ion penetration in cementitious mixtures. The chloride permeability of the cementitious mixture was reduced $89 \%$ by using $20 \%$ MK as a partial replacement of cement [11]. SF reduced the chloride permeability of SCMs mixture more than MK at $8 \%$ cement replacement level. However, using 11\%, 15\%, 20\%, and 25\% MK showed the lower chloride permeability values [11].

\section{Conclusions and recommendations}

Constituent elements of grout mix plays a vital role in controlling its' properties to a great extent. For an effective industrial application, mix design should be prepared to obtain a good strength, flowability and durability, by utilizing locally abundant supplementary cementitious materials (SCMs). This article describes about how the properties of grout are influenced by some popular SCMs. This overview will help the professionals to choose an SCM for practical application.

This overview also recommends to identifying some important properties of grout incorporating SCMs. The following recommendations are: 
1. Fire resistance of cementitious grout incorporating SCMs.

2. Properties of fibre-reinforced cementitious grout incorporating SCMs.

3. Tensile behaviour of grout containing agricultural and industrial SCMs.

Acknowledgments: The authors acknowledge Universiti Kebangsaan Malaysia for providing the necessary funding for this research through "Research University Grant" Scheme (GP-2020-K015465; GP-2020-K016180).

Conflicts of Interest: The authors declare that there is no conflict of interest.

\section{References:}

1. Anagnostopoulos, C. A. Effect of different superplasticisers on the physical and mechanical properties of cement grouts. Construction and Building Materials 2014, 50, 162-168.

2. Joshaghani, A., Moeini, M. A., Balapour, M., Moazenian, A., Effects of supplementary cementitious materials on mechanical and durability properties of high-performance non-shrinking grout (HPNSG). Journal of Sustainable Cement Based Materials 2017, DOI: 10.1080/21650373.2017.1372318

3. Baltazar LG, Henriques FMA, Jorne F. Optimisation of flow behaviour and stability of superplasticized fresh hydraulic lime grouts through design of experiments. Construction and Building Materials 2012; 35, 838-845.

4. Sakir, S., Raman, S.N., Safiuddin, M., Kaish, A. B. M. A., Mutalib, A. A. Utilization of By-Products and Wastes as Supplementary Cementitious Materials in Structural Mortar for Sustainable Construction. Sustainability 2020, 12, 3888 .

5. Kaish, A.B.M.A., Breesem, K. M., Abood, M. M. Influence of pre-treated alum sludge on properties of highstrength self-compacting concrete, Journal of Cleaner Production 2018, 202, 1085-1096.

6. Sakir, S., Raman, S.N., Kaish, A. B. M. A., Mutalib, A. A., Recent trends in development of self-flowing mortar incorporating supplementary cementitious materials, 2nd International Electronic Conference on Materials, 2 May 2016.

7. Erdoğdu Ş, Arslantürk C, Kurbetci Ş. Influence of fly ash and silica fume on the consistency retention and compressive strength of concrete subjected to prolonged agitating. Construction and Build Materials 2011, 25(3), 1277-1281.

8. Krishnamoorthy, T.S., Gopalakrishnan, S., Balasubramanian, K., Kumar, B., B.H., Rao, P. R. M., Investigations on the cementitious grouts containing supplementary cementitious materials. Cement and Concrete Research 2002, 32, 1395-1405.

9. Fonseca, F. S., Godfrey, R. C., Siggard, K., Compressive strength of masonry grout containing high amounts of class F fly ash and ground granulated blast furnace slag. Construction and Building Materials 2015,94, 71927.

10. Shannag, M. J. High-performance cementitious grouts for structural repair, Cement and Concrete Research 2002, 32, 803-808.

11. Hassan, A. A. A., Lachemi, M., Hossain, K. M.A. Effect of metakaolin and silica fume on the durability of self-consolidating concrete. Cement \& Concrete Composites 2012, 34, 801-807.

12. Ardalan, R. B., Joshaghani, A., Hooton, R. D. Workability retention and compressive strength of selfcompacting concrete incorporating pumice powder and silica fume. Construction and Building Materials 2017, 134, 116-122.

13. Wongkeo, W., Thongsanitgarn, P., Ngamjarurojana, A., Chaipanich, A., Compressive strength and chloride resistance of self-compacting concrete containing high level fly ash and silica fume, Materials and Design 2014.

14. Bilir, T., Gencel, O., Topcu, I. B. Properties of mortars with fly ash as fine aggregate. Construction and Building Materials 2015.

15. Senhadji, Y.; Escadeillas, G.; Mouli, M.; Khelafi, H.; Benosman. Influence of natural pozzolan, silica fume and limestone fine on strength, acid resistance and microstructure of mortar. Powder Technology 2014, 254, 314-323.

16. Khotbehsara, M.M.; Mohseni, E.; Yazdi, M.A.; Sarker, P.; Ranjbar, M.M. Effect of nano-CuO and fly ash on the properties of self-compacting mortar. Construction and Building Materials 2015, 94, 758-766.

17. Parghi, A.; Shahria Alam, M. Physical and mechanical properties of cementitious composites containing recycled glass powder (RGP) and styrene butadiene rubber (SBR). Construction and Building Materials 2016, 104, 34-43.

18. Ahari, R.S., Erdem, T. K., Ramyar, K. Effect of various supplementary cementitious materials on rheological properties of self-consolidating concrete Construction and Building Materials 2015, 75, 89-98 
Publisher's Note: MDPI stays neutral with regard to jurisdictional claims in published maps and institutional affiliations.

(C) 2020 by the authors. Submitted for possible open access publication under the terms

(c) and conditions of the Creative Commons Attribution (CC BY) license (http://creativecommons.org/licenses/by/4.0/). 